\title{
Separation Behavior of U(VI) and Th(IV) on a Mixed Ion Exchange Column Using 2,6-Pyridine Dicarboxylic Acid as a Complexing Agent and Determination of Trace Level Thorium in Uranium Matrix Employing High Performance Ion Chromatography
}

\author{
Vaibhavi V. Raut ${ }^{1}$, S. P. Roy ${ }^{2}$, M. K. Das ${ }^{1}$, S. Jeyakumar ${ }^{1 *}$, K. L. Ramakumar ${ }^{3}$ \\ ${ }^{1}$ Radioanalytical Chemistry Division, Bhabha Atomic Research Centre, Mumbai, India \\ ${ }^{2}$ Product Development Division, Bhabha Atomic Research Centre, Mumbai, India \\ ${ }^{3}$ Radiochemistry and Isotope Group, Bhabha Atomic Research Centre, Mumbai, India \\ Email: vvraut@barc.gov.in,roy.satyendra@yahoo.com,mkdas@barc.gov.in, ssjkumar@barc.gov.in, klram@barc.gov.in
}

Received July 24, 2013; revised August 25, 2013; accepted September 25, 2013

Academic Editor: Prof. N. Sivaraman, HBNI,

India and Head, SCSS, Chemistry Group, Indira Gandhi Centre for Atomic Research, Kalpakkam-603102, INDIA

Copyright (C) 2013 Vaibhavi V. Raut et al. This is an open access article distributed under the Creative Commons Attribution License, which permits unrestricted use, distribution, and reproduction in any medium, provided the original work is properly cited.

\begin{abstract}
Retention behavior of $\mathrm{U}(\mathrm{VI})$ and Th(IV) as their 2,6-pyridine dicarboxylic acid (PDCA) complexes on reversed phase and ion exchange (cation, anion and mixed ion exchange) columns was studied and based on the results, a simple ion chromatography method for the determination of trace level thorium in uranium oxide using $0.075 \mathrm{mM}$ 2,6-pyridine dicarboxylic acid (PDCA) and $1 \mathrm{M} \mathrm{KNO}_{3}$ in $1.2 \mathrm{M} \mathrm{HNO}_{3}$ as eluent (flow rate $1 \mathrm{~mL} / \mathrm{min}$ ) was proposed. The advantage of the developed method is that the separation of uranium matrix is not required prior to the ion chromatographic determination of trace Th. Separation was carried out on a mixed ion exchange stationary phase and a $10^{-4} \mathrm{M}$ arsenazo (III) solution was used as post column reagent for detecting the separated metal ions. The separation of Th from uranium using PDCA in the present investigation is attributed through cation exchange mechanism. A calibration plot was constructed by following the standard addition method over the concentration range of 0.25 to $10 \mathrm{ppm}$ of Th in the presence of uranium matrix, which resulted in a linear regression coefficient of 0.9978 . The precision of the method was better than $5 \%$ and the LOD for Th was found to be $0.1 \mathrm{ppm}(\mathrm{S} / \mathrm{N}=3)$. The method has been validated by comparing the results with the results obtained from ICP-MS analysis where the Th is separated from the uranium matrix. The proposed method is simple, rapid, accurate and cost effective compared to techniques like ICP-MS or ICP-AES and is suitable for the routine kind of analysis.
\end{abstract}

Keywords: Ion Chromatography; Uranium; Thorium; 2,6-Pyridine Dicarboxylic Acid

\section{Introduction}

The development of fast breeder reactors in India is inevitable as India has limited resources of uranium and the vast thorium resources require breeder cycle for exploitation [1,2]. The Proto Type Fast Breeder Reactor (PFBR), a first commercial fast breeder reactor of India, is under construction and it will use a mixed uranium-plutonium oxide (MOX) as fuel. Thorium is a trace impurity associated with all uranium based fuels [3]. Thorium, on irra-

${ }^{*}$ Corresponding author. diation with a neutron produces ${ }^{233} \mathrm{U}$, is a useful fissile isotope. Small amounts of ${ }^{232} \mathrm{U}$ isotope are also produced along with ${ }^{233} \mathrm{U}$. ${ }^{232} \mathrm{U}$ is an undesirable isotope as its radioactive decay chain produces short-lived and gamma emitting radionuclides ${ }^{212} \mathrm{Bi}$ and ${ }^{208} \mathrm{Tl}$, leading to high radiation exposure [4]. Hence, the uranium based fuels that are used in the fast reactors has stringent specification for Th and in India, the limit is fixed as $200 \mathrm{ppm}_{\mathrm{w}}$ [5]. Hence, determination of trace Th in uranium is indispensible in the chemical quality control of fast reactor fuels. 
Although different analytical techniques are available for the determination of $\mathrm{Th}$ at trace levels [6-8], they require quantitative separation of $\mathrm{Th}$ from uranium matrix which is a prerequisite for analytical determination. An ICP-MS method [9] was earlier reported from our laboratory for the determination of Th in uranium matrix, which employed a two-stage separation sequence involving an initial solvent extraction for the removal of uranium matrix followed by an ion exchange purification to get the required quality of sample solutions suitable for ICP-MS analysis. The conventional separations followed by instrumental analysis employing ICP-MS or AES are time consuming and expensive. To adopt on routine basis, a reliable, cost effective and rapid analytical method is desirable.

Ion chromatography (IC) and High performance liquid chromatography (HPLC) are promising techniques for the separation of polyvalent metal cations by adding suitable complexing agents in the mobile phase [10-13]. Many chromatographic studies have been reported on the selective separation of $\mathrm{Th}$ and $\mathrm{U}$ in variety of samples using reversed phase surfaces with weak organic acids as chelating agents $[14,15]$. In these separations, the extent of separation depended on the nature of the metal complexes formed and their conditional stability constants [16]. Interestingly, it is reported that the elution order of $\mathrm{U}$ and $\mathrm{Th}$ on a reversed phase surface could be altered by selecting a suitable complexing agent. For example, an elution order of Th followed by $\mathrm{U}$ was observed in a RP surface when $\alpha$-hydroxy isobutyric acid ( $\alpha$-HIBA) was used as a complexing agent $[17,18]$. However, this elution order got reversed when mandelic acid (MA) was used in place of $\alpha$-HIBA [19]. The change in elution order may be explained on the basis of differences in the complexing abilities of the ligands with respect to individual metal cation, effective charge, thermodynamic and kinetic stabilities and hydrophobicities of the metal complexes formed.

Although $\alpha$-HIBA and MA are widely used as complexing agents in the separation of $U$ and Th, 2,6-pyridine dicarboxylic acid (PDCA), a non-hydroxy dicarboxylic acid, has been identified as a promising ligand for the separation of heavy metal ions [20-23]. The reversed phase surfaces dynamically modified with PDCA $[22,24]$ showed stronger retention for U(VI) than Th(IV) due to the high affinity exhibited by the $\mathrm{UO}_{2}{ }^{2+}$ ion for PDCA [20]. A study reports [22] that dynamic modification of a small PRP column with $0.1 \mathrm{mM}$ PDCA in $1 \mathrm{M}$ $\mathrm{KNO}_{3}$ and $0.5 \mathrm{M} \mathrm{HNO}_{3}$ could separate some of the acid hydrolysable heavy metal ions like $\mathrm{U}, \mathrm{Th}, \mathrm{Zr}$, etc. It also states that the lanthanides and other transition metal cations have no retention on the column and get excluded at the solvent front.

Other than RP columns, ion exchange columns were also used for the separation of $U$ and Th. The ion chro- matographic separation of $U$ and Th using pure ion exchange separation is difficult due to the large differences in their distribution ratios. This is because the $\mathrm{UO}_{2}{ }^{2+}$ and $\mathrm{Th}^{4+}$ ions have considerable differences in their ion exchange affinity. Separation of $\mathrm{U}(\mathrm{VI})$ as $\mathrm{UO}_{2}{ }^{2+}$ on a low capacity strong cation exchanger has been reported [25]. Even though few studies reported the separation of $U$ and Th from water and geological samples using a pure cation exchange column with gradient elution of a mobile phase consisted of $\mathrm{HCl}$ and $\mathrm{Na}_{2} \mathrm{SO}_{4}$ [26,27], use of hydrochloric acid as eluent was not recommended for routine analysis due to its corrosiveness, which demanded utmost care on the instrument maintenance. Earlier in our laboratory, we have separated uranium and thorium using a short length cation exchange column using a mobile phase consisting of $0.08 \mathrm{mM}$ PDCA in $0.24 \mathrm{M} \mathrm{KNO}_{3}$ and $0.22 \mathrm{M} \mathrm{HNO}_{3}(\mathrm{pH} \sim 0.6)$ [23]. This method was found suitable for the rapid separation of both $U$ and Th at trace level concentrations; however, it would not be possible to extend the procedure when one of the metal ions was at higher concentrations.

The studies that reported the basis of RP-surface modifications and ion exchange separations were capable of providing good separation between $\mathrm{U}$ and $\mathrm{Th}$, provided their concentrations were comparable. However, the separation of $U$ and $T h$ is a difficult task when one of these metal ions presents in large amount. When determining one metal ion at trace level in the presence of large excess of other, the system loses its capacity, resulting in poor resolution between the analytes [21]. The most practicable way is to remove matrix element by means of conventional methods like solvent extraction, column chromatography and ion exchange prior to the IC or HPLC. Such sample preparation procedures are not only time consuming and laborious but also susceptible to cause inconsistency in the recoveries of the analyte of interest. Moreover, methods that follow pre-separation followed by instrumental analysis demand the use of certified reference materials to assess the recoveries.

Since the objective of this study is to separate trace thorium from the dissolved uranium oxide samples by direct sample injection, one of the desired conditions to realize the objective is to have an elution order of Th(IV) followed by U(VI) so as to get the elution of Th first and then the matrix U. This elution order can be obtained by separating them on a reversed phase column (modified and unmodified) using $\alpha$-HIBA as eluent [11]. But, the separation of Th in presence of bulk $U$ could not be realized by following the reported procedures. A good separation of lanthanides, Th and $\mathrm{U}$ at relatively large concentrations was reported [17] where the C-18 RP column was coated with bis-2-ethylhexyl succinamic acid (BEHSA). However, the same study showed that it could not separate $T h$ from $U$ when the uranium concentration in the sample was more than $5 \mathrm{mg} / \mathrm{mL}$. Mandelic acid, an- 
other complexing agent frequently used in the separation of $U$ and $T h$, could not be used as it brings reversed order of elution i.e. $\mathrm{U}$ followed by $\mathrm{Th}$ and both uranium and thorium mandelate complexes interact hydrophobically with the reversed phase surface and exhibit significant retentions. A similar elution order was reported in the case of cation exchange chromatography as uranium forms weaker cationic species with the frequently used eluents like hydrochloric and nitric acids [28]. This elution order may be useful in the present case only when $\mathrm{U}(\mathrm{VI})$ has no or least interaction with stationary phase so that it can get eluted at the solvent front. The realization of this condition obliviously depends on the selection of an appropriate stationary phase and a suitable complexing agent. Ion exchange separation of metal ions can be affected by adding weak organic acids in the mobile phase, which reduces or alters the effective charge of the metal ions by forming either cation, neutral or anion complexes and the nature and stability of the metal complexes would decide the method of ion exchange (anion or cation) separation. Nowadays, stationary phases having both cation and anion exchange capacities are found to be more useful in separating heavy and transition metal ions [29] because the separation is controlled by the concentrations of free metal ions and the various insitu metal complexes formed, which are in an equilibrium with each other [30]. One such mixed ion exchanger namely Ion Pac CS5A has been widely used for the separation of lanthanides and transition metal cations in several matrices [31-33].

Hence it is decided to examine Ion Pac CS5A mixed ion exchanger column in the present investigation for the separation of traces of Th from bulk of $U$ as it 1) contains both strong anion and cation exchangers (anion exchange capacity: $40 \mu \mathrm{eq} /$ column and cation exchange capacity: $20 \mu \mathrm{eq}$ (column), and 2) displays anion and cation exchange properties while separating the metal cations by choosing an appropriate complexing agent [34]. In the present investigation, PDCA has been chosen as complexing agent as it has high affinity for complex formation with polyvalent metal cations. The main advantages in using PDCA as a complexing agent are: 1) it can be used with low $\mathrm{pH}$ or high acid concentration and 2) the concentration of PDCA required in the mobile phase to facilitate the separation is very low $\left(\sim 10^{-5} \mathrm{M}\right)$ compared to the concentrations of the hydroxy carboxylic acids $\left(\sim 10^{-1} \mathrm{M}\right)$ required. Since the nuclear fuel samples (mg amounts) are often dissolved in mineral acids and subsequently aliquots are made out of this solution for wet analyses, it is desirable to use PDCA as complexing agent, which would enable the direct injection of the samples into the system.

The aim of this investigation was to develop a rapid and reliable method for the separation and determination of trace level thorium in uranium oxide using a mixed ion exchanger column and PDCA as a complexing agent.

\section{Experimental}

\subsection{Instrumentation}

The IC system used in the present study was DX500 (Dionex CA, USA). It consisted of a solvent delivery pump (GP-50) and an absorption detector (AD20). A pneumatic post column reagent addition facility consisting of a $1000 \mathrm{~mL}$ reservoir bottle, gas pressure gauge to control the flow rate of the gas, a T-junction and a $75 \mu \mathrm{L}$ capacity reaction coil was placed between the separator column and the detector. The samples were injected through a $50 \mu \mathrm{L}$ loop fitted to a Rheodyne six port injecttor. The separator columns used were 1) Ionpac CS5A $(4.6 \times 250 \mathrm{~mm})$ with CG5A guard column $(4.6 \times 50 \mathrm{~mm})$ (Dionex CA, USA), 2) Ionpac AS11 HC $(4.6 \times 250 \mathrm{~mm})$ with AG11 guard column $(4.6 \times 50 \mathrm{~mm})$ (Dionex CA, USA) and 3) IC Pak Cation, $4.6 \times 50 \mathrm{~mm}$ (Waters, USA). The $\mathrm{pH}$ measurements were made on a CL-5 pH meter (Toshniwal, India).

\subsection{Reagents}

All the reagents were of analytical grade (AR). Standard stock solution of uranium was prepared by dissolving nuclear grade $\mathrm{U}_{3} \mathrm{O}_{8}$ and its concentration was determined by biamperometry method [35]. Standard stock solution of $\mathrm{Th}\left(97.8 \mathrm{mg} \mathrm{ml}^{-1}\right)$ was prepared by dissolving nuclear grade $\mathrm{Th}\left(\mathrm{NO}_{3}\right)_{4}$ (IRE, India) in $3 \mathrm{M} \mathrm{HNO}_{3}$ and the Th concentration was determined by complexometric titration with EDTA using xylenol orange as indicator. 2,6pyridine dicarboxylicacid (PDCA) (99\%, Aldrich Chemical corporation Inc.) was used as such. 0.01 M PDCA solution was prepared in water and appropriate volume of this solution was used in the preparation of mobile phase. Nitric acid was of suprapure grade (Merck, India). All solutions were prepared using high purity deionised water (18.2 M $\Omega$ ) obtained from a Milli Q water system (Millipore, USA). The eluents were filtered through nylon 6,6 , membrane filters $(0.45 \mu \mathrm{m})$ prior to their use. A post column reagent of $4.5 \times 10^{-5} \mathrm{M}$ Arsenazo-III in $0.1 \mathrm{~N}$ $\mathrm{HNO}_{3}$ was added through a PEEK make T-junction with a flow rate of $0.8 \mathrm{ml} \mathrm{min}^{-1}$ for the detection of the separated metal ions at $655 \mathrm{~nm}$.

\section{Results and Discussion}

\subsection{Preliminary Investigation}

Earlier we reported the separation of $U$ and $T h$ as their PDCA complexes using cation exchange column with a mobile phase of $0.08 \mathrm{mM}$ PDCA in $0.24 \mathrm{M} \mathrm{KNO}_{3}$ and 
$0.22 \mathrm{M} \mathrm{HNO}_{3}(\mathrm{pH} \sim 0.6)$ [23]. A study that dealt with the chelation ion chromatography (CIC) separation could successfully separate $\mathrm{Th}(\mathrm{IV})$ and $\mathrm{U}(\mathrm{VI})$ on a neutral polystyrene resin column dynamically modified with PDCA [14]. Based on the reported studies, to start with, an eluent composition of $0.1 \mathrm{mM}$ PDCA in $1 \mathrm{M} \mathrm{KNO}_{3}$ and $0.5 \mathrm{M} \mathrm{HNO}_{3}(\mathrm{pH} \sim 0.3)$ was arbitrarily used with the mixed ion exchanger column viz. Ionpac CS5A. With this eluent, there can be three possible mechanisms in which the metal complexes can interact with the stationary phase and they are: 1) cation-exchange 2) anion-exchange provided the metal ions form anionic complexes with PDCA and 3) chelation ion chromatography. Interestingly, unlike the modified RP column, the mixed ion exchange column exhibited strong retention for Th (IV) whereas $\mathrm{U}(\mathrm{VI})$ got eluted immediately after the solvent front. Hence, the elution order observed in the present case is $\mathrm{U}(\mathrm{VI})$ followed by Th (IV), which is similar to that of the elution order obtained with strong cation exchange stationary phase $[23,26,27]$. This indicates that in the case of mixed ion exchanger, the chelation exchange mechanism responsible for retaining U (VI) and Th (IV) on the RP substrate is insignificant, probably the mixed ion exchanger column was not sufficiently modified with PDCA to get the elution order similar to that of the RP column. Since the observed elution order is similar to that of the order obtained with cation exchange separation, it is necessary to study the role of anion exchanger in the column, if any.

\subsection{Effect of Concentration of PDCA}

In order to understand the effect of PDCA concentration on the retention of both $\mathrm{U}(\mathrm{VI})$ and $\mathrm{Th}(\mathrm{IV})$, concentration of PDCA in the mobile phase was varied from 0.04 to 0.2 $\mathrm{mM}$ by keeping the concentrations of other two components namely $\mathrm{KNO}_{3}(1 \mathrm{M})$ and $\mathrm{HNO}_{3}(0.5 \mathrm{M})$

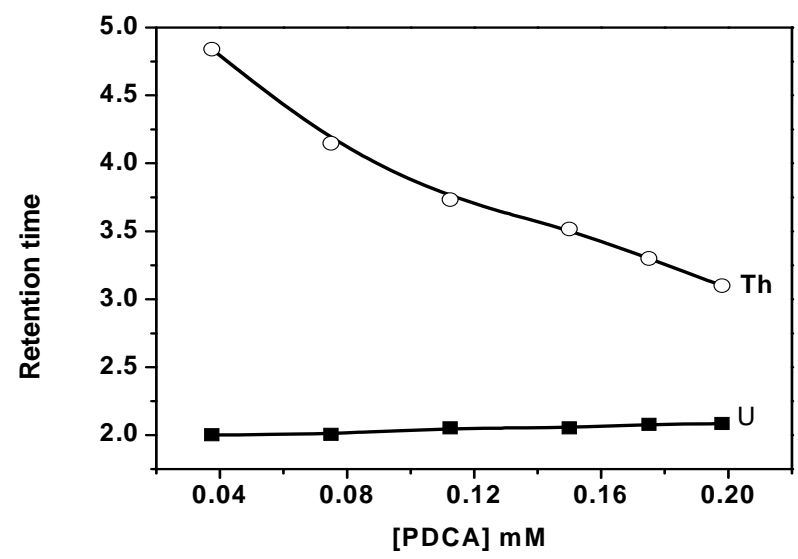

Figure 1. Effect of concentration of PDCA on the retention of $U$ and Th separated on a mixed ion changer column. The concentrations of $\mathrm{KNO}_{3}$ and $\mathrm{HNO}_{3}$ in the eluents were kept as $1 \mathrm{M}$ and $0.5 \mathrm{M}$ respectively. constant. The variation in $\mathrm{pH}$ of the eluent was insignifi cant while varying the PDCA concentration because the concentra- tion of $\mathrm{HNO}_{3}$ in the eluent was large compared to the concentration of PDCA. The retention trend obtained is shown in Figure 1. Increasing PDCA concentration in the mobile phase had virtually no effect on the retention of $\mathrm{U}(\mathrm{VI})$ whereas the retention of Th(IV) was drastically reduced.

The PDCA concentration was not increased beyond $0.2 \mathrm{mM}$ because 1) the resolution between the two peaks was poor and 2) the detection sensitivity of the Th(IV)arsenazo-III complex reduced significantly beyond 0.15 $\mathrm{mM}$ PDCA. The observed retention behavior of U(VI) shows that it has least retention on the column and this can occur only when U(VI) forms a stable neutral complex with PDCA. This is because the formation of either a cation or an anion complex of U(VI)-PDCA would have exhibited significant retention since the column has both cation and anion exchange sites. The equilibrium distribution of PDCA (uncomplexed) species differs with $\mathrm{pH}$. PDCA is a dicarboxylic acid having $\mathrm{pK}_{1}=2.10$ and $\mathrm{pK}_{2}=4.68$ for an ionic strength of $0.1 \mathrm{M}$ [36]. It has been reported that PDCA $\left(\mathrm{H}_{2} \mathrm{~L}\right)$ predominantly exists as $\mathrm{HL}^{-}$form when the eluent $\mathrm{pH} \leq 1$ whereas at higher (alkaline) $\mathrm{pH}$, it can be transformed into $\mathrm{L}^{2-}$ form [34]. Since the eluent $\mathrm{pH}<1$, the existence of $\mathrm{HL}^{-}$form is predominant than that of $\mathrm{L}^{2-}$ form of the ligand. Hence, $\mathrm{U}(\mathrm{VI})$ may be forming probably a $1: 2$ with $\mathrm{HL}^{-}$or $1: 1$ complex with $\mathrm{L}^{2-}$ form of PDCA. Though we cannot offer any evidence for the formation of the neutral complex(es), the strong retention of U(VI)-PDCA complex on a reversed phase surface [14] supports this assumption. Theoretically, though a neutral complex in equilibrium with either its pure metal ions or other kind of complex cations can have feeble interaction on cation exchange sites provided the complex formed is kinetically labile. In the present case, the complex formed has no interaction with both anion and cation exchangers and this may be due to high stability of the U-PDCA neutral complex formed. Since there was no significant change in the retention of U(VI) while increasing PDCA concentration in the eluent, the formation of weak anionic complex of UPDCA was not appreciable in the present case.

In the case of $\mathrm{Th}(\mathrm{IV})$, it exhibited significant retention on the mixed ion exchanger column. Elution with increasing PDCA concentration in the mobile phase decreased the retention of $\mathrm{Th}(\mathrm{IV})$. The proposed cation exchange models in literature [37] report that increasing the concentration of complexing agent decreases the retention time of metal ions due to their formation as neutral or weak anionic complexes. Whereas in anion exchange model reports that only strong anion metal-ligand complexes can interact with the anion exchange sites and hence, increasing the concentration of complexing agent 
in the eluent would increase in the retention time. In order to conclude about the probable nature of the metal complexes and their interaction with ion exchange sites, it is necessary to study the retention of $U$ or Th with the components of eluent individually.

Initially, separations were carried out by varying the concentration of PDCA between $0.02 \mathrm{mM}$ to $0.4 \mathrm{mM}$ in $0.2 \mathrm{M} \mathrm{HNO}_{3}$ (necessary to avoid hydrolysis of $\mathrm{U}$ and $\mathrm{Th}$ ) without taking $\mathrm{KNO}_{3}$ in the mobile phase. It was observed that with $0.02 \mathrm{mM}$ PDCA, U appeared at 4.0 minutes whereas the same appeared at 2.7 minutes when the PDCA concentration was increased to $0.1 \mathrm{mM}$ and subsequent increase of PDCA up to $0.4 \mathrm{mM}$ did not change the retention time significantly. In contrast, Th(IV) peak did not appear at all. A similar observation was made when pure $\mathrm{HNO}_{3}(0.5$ to $2 \mathrm{M})$ or pure $\mathrm{KNO}_{3}$ $(0.2$ to $1.8 \mathrm{M})$ was used as eluent. Eluents with mixture of $\mathrm{HNO}_{3}$ and $\mathrm{KNO}_{3}$ of varying concentrations were also used and there was no difference in the retention of U(VI) compared to that of the pure $\mathrm{HNO}_{3} / \mathrm{KNO}_{3}$. However, interestingly it was observed that $\mathrm{Th}(\mathrm{IV})$ appeared when the $\mathrm{pH}$ of the mixed eluent was less than 1. Further, it was seen that the elution of thorium was so slow that it resulted in a broad peak. Therefore, it may be concluded that in the absence of PDCA in the eluent, the thorium elution with $\mathrm{KNO}_{3}+\mathrm{HNO}_{3}$ may be due to the formation of its nitrato complex and the formation of such nitrato complex is $\mathrm{pH}$ dependent.

Therefore, it is seen from the experiments carried out with $\mathrm{PDCA}, \mathrm{KNO}_{3}$ and $\mathrm{HNO}_{3}$ individually as well as with various combinations that for the separation of Th(IV), for the purpose of analytical determination, a mobile phase with the combination of all three components is required. The observations showed that at this low concentration of PDCA, the elution of Th(IV) occurred only when a $\mathrm{KNO}_{3}$ is added along with minimum $0.1 \mathrm{M} \mathrm{HNO}_{3}$ concentration. It has been observed that eluents with PDCA concentration above $0.08 \mathrm{mM}$ were not found suitable for separating trace $\mathrm{Th}$ in the presence of large excess of uranium. Therefore, the PDCA concentration has been fixed at $0.075 \mathrm{mM}$. This concentration would reduce the interactions between $\mathrm{UO}_{2}{ }^{2+}$-PDCA complex with the stationary phase, which is desirable to realize the elution of $U$ peak immediately after or at the excluded peak.

\subsection{Effect of Concentration of $\mathrm{KNO}_{3}$}

The retention trends of U(VI) and Th(IV) shown in Figure 1 suggest that U(VI) predominantly forms a neutral complex and gets eluted immediately after the excluded peak and Th(IV) forms weak neutral or anionic complex and most probably, the mechanism responsible for the retention of Th(IV) on the column is due to cation exchange. However, addition of relatively high concentra- tion of $\mathrm{KNO}_{3}$ may suppress the ion exchange process due to the presence of large concentration of $\mathrm{K}^{+}$ions (acts as competing cation). It was observed that the retention time of U(VI) was unaltered whereas the retention time of $\mathrm{Th}(\mathrm{IV})$ decreased when the concentration of $\mathrm{KNO}_{3}(0.2$ to $1.8 \mathrm{M}$ ) was increased in the mobile phase and by keeping the PDCA and $\mathrm{HNO}_{3}$ concentrations as 0.075 $\mathrm{mM}$ and $0.2 \mathrm{M}$, respectively.

The retention time of Th(IV) decreases drastically in the concentration range of 0.2 to $1.2 \mathrm{M}$ and subsequently there was a little decrease up to $1.8 \mathrm{M}$. The drastic reducetion in retention time may be attributed due to two reasons: 1) increasing $\left[\mathrm{KNO}_{3}\right]$ increases the ionic strength of the eluent. While using cation-exchange column with complexing eluent, the affinity of metal ions for ionexchange resins decreases as ionic strength increases and therefore, the retention time decreases and 2) $\mathrm{NO}_{3}^{-}$ from $\mathrm{KNO}_{3}$ may be competing with PDCA in complex formation. To identify the role of $\mathrm{KNO}_{3}$, separations were carried out with PDCA and $\mathrm{HNO}_{3}$ combinations where the nitrate was supplied in the form of $\mathrm{HNO}_{3}$. For instance, instead of $0.5 \mathrm{M} \mathrm{HNO}_{3}+0.5 \mathrm{M} \mathrm{KNO}_{3}+0.075$ mM PDCA (pH 0.3) an eluent of $0.075 \mathrm{mM}$ PDCA in 1 $\mathrm{M} \mathrm{HNO}_{3}$ was prepared and $\mathrm{pH}$ was adjusted by adding $\mathrm{LiOH}$. It was seen that with the latter mobile phase composition, Th could not be eluted from the column. This suggests that $\mathrm{K}^{+}$is acting as competing ion which reduces the bare metal ions ( $\mathrm{U}$ and $\mathrm{Th}$ ) interactions with ion exchange sites.

Equation for cation (complex ion) exchange is expressed as

$$
\log D_{m}=\log K_{M A}-\log a_{M(L)}+n \log C-n \log \left[A^{+}\right]
$$

where $D_{m}$ is the distribution coefficient of the metal in presence of complexing agent, $\mathrm{K}_{\mathrm{MA}}$ is the selectivity coefficient between the metal and competing cation, $\mathrm{a}_{\mathrm{M}(\mathrm{L})}$ is complex formation coefficient, $\mathrm{C}$ is the capacity of the ion exchanger and $\left[\mathrm{A}^{+}\right]$is the concentration of the competing cation.

The distribution coefficient $\left(\mathrm{D}_{\mathrm{m}}\right)$ of the metal is a function of the concentration of the competing cation $\left(\mathrm{A}^{+}\right)$ and that of the complexing agent in the mobile phase. Since in the present case the competing cations in the mobile phase are $\mathrm{K}^{+}$and $\mathrm{H}^{+}$, the elution mainly depends on the concentration of $\mathrm{K}^{+}$ions as it has high selectivity over $\mathrm{H}^{+}$. On increasing the $\mathrm{KNO}_{3}$ concentration in the eluent decreased the retention times of only Th(IV) whereas the retention times of U(VI) was unaffected throughout the concentration range (Figure 2(a)). Th(IV) retention times decreased steadily as the $\mathrm{KNO}_{3}$ concentration was raised up to $1.2 \mathrm{M}$ and subsequent increment of rise in $\mathrm{KNO}_{3}$ concentration did not reduce the retention times appreciably. As this trend is expected in the case of cation exchange of Th(IV), a plot of log k (reten- 


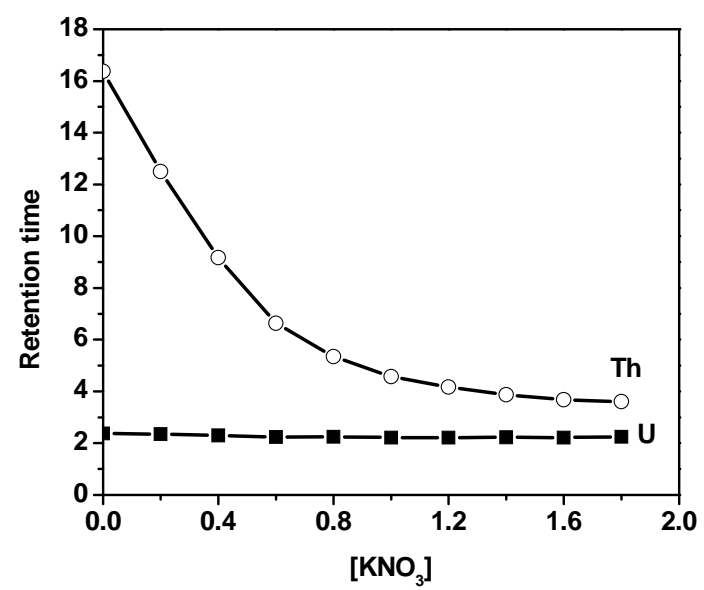

(a)

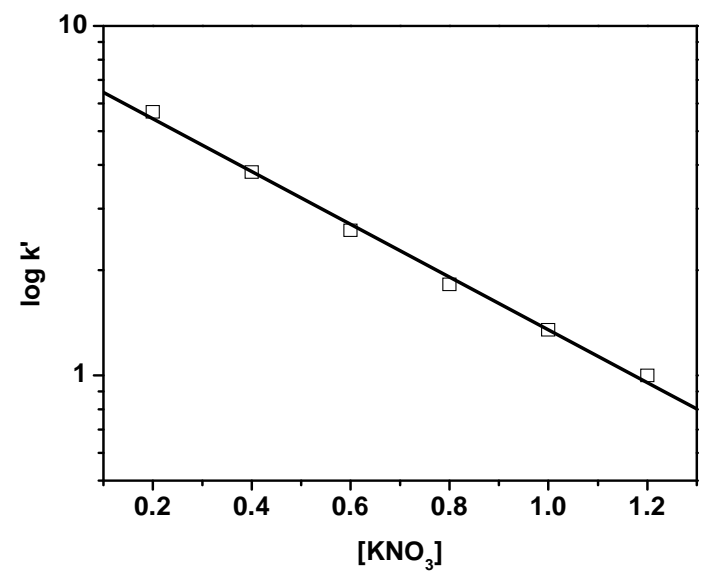

(b)

Figure 2. (a) Effect of concentration of $\mathrm{KNO}_{3}$ on the retention of $U$ and Th separated on a mixed ion exchanger column (the concentrations of PDCA and $\mathrm{HNO}_{3}$ in the eluents were $0.075 \mathrm{mM}$ and $0.5 \mathrm{M}$ respectively) and (b) plot of $\log \mathrm{k}$ (retention factor) of $\mathrm{Th}$ against $\left[\mathrm{KNO}_{3}\right]$.

tion factor) against $\mathrm{KNO}_{3}$ concentration over the range of 0 - 1.2 M brought a straight line with negative slope (Figure 2(b)) indicating the separation is predominantly by cation exchange mechanism. The optimum $\mathrm{KNO}_{3}$ concentration was fixed as $1.0 \mathrm{M}$ as this provided the desired separation between U(VI) and Th(IV).

\subsection{Effect of Concentration of $\mathrm{HNO}_{3}$}

Addition of $\mathrm{HNO}_{3}$ and its concentration plays an important role in controlling the effective ligand concentration in the mobile phase, which decides the nature of metalcomplex. In addition, $\mathrm{HNO}_{3}$ prevents the hydrolysis of metal cations as these heavy metal ions belong to acid hydrolysable group. Moreover, the $\mathrm{H}^{+}$ions from the nitric acid also act as the competing ion during the elution of metal cations or cation complexes. To investigate the influence of $\mathrm{HNO}_{3}$ concentration on the elution, two sets of experiments were conducted. In the first set, $\mathrm{HNO}_{3}$ concentration was varied over a range between 0.5 and $1.5 \mathrm{M}$.

It was expected that increasing acid concentration would reduce the effective concentration of ligand, which would affect the complexation of U(VI) leaving more metal cations and in such case, the retention times for both $\mathrm{Th}(\mathrm{IV})$ and U(VI) are expected to be increased. However, there was no appreciable change in the retention times observed. Interestingly, there was a steady improvement in the symmetry of Th(IV) peak was observed. In the second set, the $\mathrm{pH}$ of the mobile phase was varied from 0.3 to 4.0 . For preparing the eluents, dilute nitric acid of appropriate concentration was used and final $\mathrm{pH}$ adjustment was done with dilute $\mathrm{LiOH}$ solution. Increasing eluent $\mathrm{pH}$ caused the retention times of $\mathrm{Th}(\mathrm{IV})$ to decrease and of $\mathrm{U}(\mathrm{VI})$ to increase. In addition, the order of elution reversed from pH 2 onwards (Figure 3). There are two ways in which this can be explained. First, increase of eluent $\mathrm{pH}$ leads to increase in the effective ligand $\left(\mathrm{HL}^{-}\right)$concentration and therefore, $\mathrm{U}(\mathrm{VI})$ tends form anion complex, which interacts with anion exchanger resulting increasing trend in the retention. On the other hand, it has not resulted in change in the complex forming behavior of Th(IV) significantly and hence, retention time decreased. There could also be a possibility of column modification due to the hydrophobic interactions between the phenyl group of PDCA and the polystryrene-divinyl benzene skeleton of the resin. On increasing $\mathrm{pH}$ of the eluent, the dissociation of acid groups on the immobilized chelating ligand produces an increase in the conditional stability constants of the surface metal complexes and it causes the retention times of the metal ions to increase [15]. Between Th(IV) and U(VI), it has been reported that the U(VI)-PDCA (1:1) complex has high stability constant $\left(\log \mathrm{K}_{1}=4.72\right)$ [38] and hence, it is more retained than $\mathrm{Th}(\mathrm{VI})$. The existence of this mechanism would have been confirmed only by carrying out separations at higher $\mathrm{pH}$ levels. However, such studies are not affordable in this case as the hydrolysis of heavy metal ions cannot be prevented.

From the analytical point of view, considering the desired order of elution, separation factor and other chromatographic parameters, it is desirable to have higher concentration of $\mathrm{HNO}_{3}$ and accordingly the $\mathrm{HNO}_{3}$ concentration was fixed as $1.2 \mathrm{M}$ in the mobile phase.

\subsection{Elution with a Pure Cation Exchange Column}

Preceding investigations suggest that the elution behavior of Th(IV) was mainly due to the cation exchange mechanism. On the other hand U(VI) was eluted as its neutral complex, which gets eluted immediately after the excluded peak indicating that it has least interaction with both cation and anion exchangers. It has been seen that a 


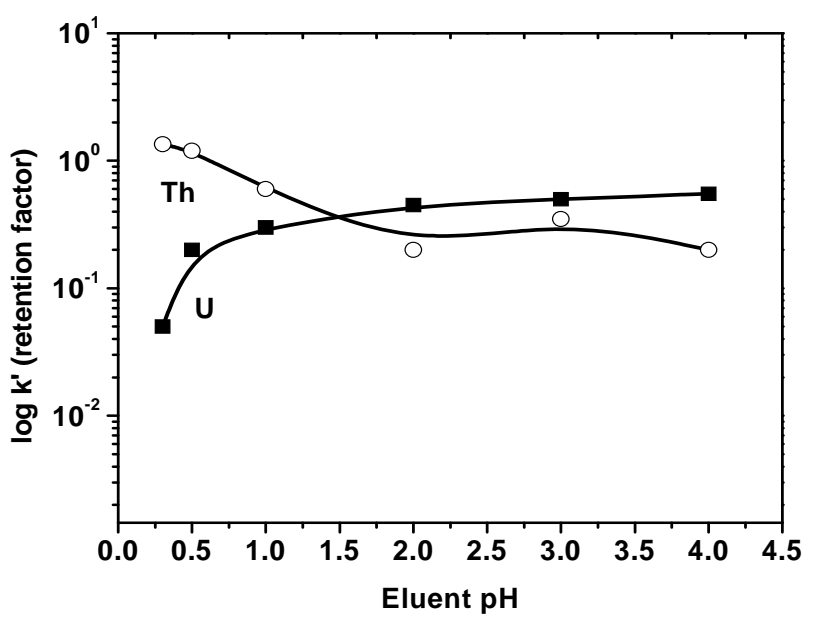

Figure 3. Effect of eluent $\mathrm{pH}$ on the retention of $\mathrm{U}$ and $\mathrm{Th}$ on a mixed ion exchanger column. The [PDCA] and $\left[\mathrm{KNO}_{3}\right]$ were $0.075 \mathrm{mM}$ and $1.0 \mathrm{M}$ respectively.

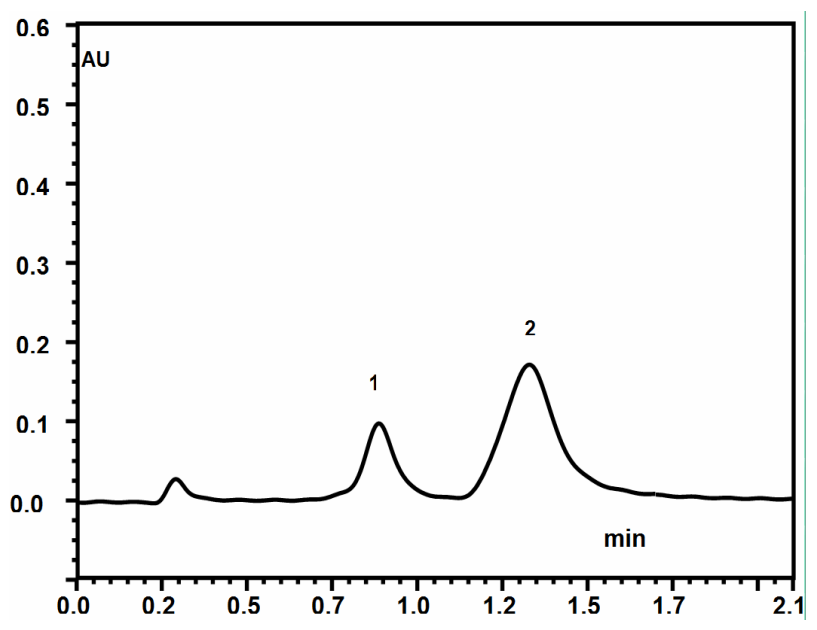

Figure 4. Typical chromatogram obtained for a standard solution of $\mathrm{U}(\mathrm{VI})$ and $\mathrm{Th}(\mathrm{IV})$ using cation exchanger column. Peaks (1) U(VI) - 3 ppm and (2) Th(IV) 3 ppm. Column: IC Pak Cation $(4.6 \times 50 \mathrm{~mm})$. Eluent: $0.1 \mathrm{mM}$ PDCA and $0.12 \mathrm{M} \mathrm{KNO}_{3}$ in $0.1 \mathrm{M} \mathrm{HNO}_{3}$; Flow rate: $1 \mathrm{ml} / \mathrm{min}$. Detection: Post column addition of $4.5 \times 10^{-5} \mathrm{M}$ arsenazo-III and detection at $656 \mathrm{~nm}$.

mobile phase of $0.1 \mathrm{mM}$ PDCA and $0.12 \mathrm{M} \mathrm{KNO}_{3}$ in 0.1 $\mathrm{M} \mathrm{HNO}_{3}$ brought good separation between $\mathrm{U}(\mathrm{VI})$ and $\mathrm{Th}(\mathrm{IV})$ and Figure $\mathbf{4}$ shows a typical chromatogram obtained. The order of elution was as same as that of the one obtained with the mixed ion exchanger column. Effects of concentrations of PDCA and $\mathrm{KNO}_{3}$ on the retention of Th(IV) showed similar trend in both mixed ion exchange and cation exchange columns. This suggests that the separation of $\mathrm{Th}(\mathrm{IV})$ is mainly due to cation exchange. In order to understand the separation with mixed ion exchange column and the role of anion exchange, it is necessary to carry out separations with pure anion exchange column too.

\subsection{Separation with Pure Anion Exchange Column}

When similar investigations were carried out with a pure anion exchange column (IonPac AS11 HC column), the elution order was reversed where Th peak appeared immediately after the excluded peak followed by $\mathrm{U}$. while increasing the PDCA concentration (from $0.08-0.5 \mathrm{mM}$ ) in the mobile phase it was observed that there were no significant changes in the retention time of both $\mathrm{U}$ and Th. This indicates that up to $0.5 \mathrm{mM}$ PDCA both $\mathrm{U}$ and Th are not forming stable anionic complexes. This observation suggests that Th may be forming weak anionic and neutral complexes with PDCA. In the present case, the appreciable retention of $U$ cannot be explained on the basis of formation of anionic complex because the retention time did not increase while increasing the PDCA concentration. Probably the neutral U-PDCA complex may be interacting on the surface of the column hydrophobically as it showed in the case of reverse phase surface. Therefore, it may be concluded that the cation exchange sites of the mixed ion exchange column play predominant role in the separation of $U$ and Th. However, the anion exchange sites present in the mixed ion exchange column may be reducing the hydrophobic interaction of U-PDCA neutral complex, though we cannot offer any evidence.

\subsection{Effect of Other Metal Ions}

Since the uranium oxide fuel samples are expected to have other metallic impurities like $\mathrm{Fe}, \mathrm{Cd}, \mathrm{Cu}, \mathrm{Ca}, \mathrm{Mg}$, $\mathrm{Ni}, \mathrm{Cr}, \mathrm{Mn}, \mathrm{Mo}$, rare earth elements etc. (within the specification limits), separations were carried out in the presence of these metal ions to observe the interference effects, if any, during the separation of Th. For this purpose, two synthetic sample solutions were prepared and used. The first solution was a mixture of thorium with transition metals ( $\mathrm{Ca}$ and $\mathrm{Mg}$ were also added) and the second one consisted thorium and mixture of all lanthanides. The individual metal ion to Th concentration ratio was kept ten in both the solutions. It has been observed that the first solution did not give any peak whereas the second solution containing mixture of lanthanides showed a small triplet peak after the uranium peak with very poor detection sensitivity. Therefore, the formulated eluent composition was found to be suitable for the interference free determination of Th. A typical chromatogram obtained for a standard solution containing $\mathrm{U}$ and $\mathrm{Th}$ is shown Figure 5.

\subsection{Effect of Matrix ion on the Separation of Th}

Under the optimized separation conditions, the uranyl ion eluted very close to the excluded peak and the retention capacity factor $\left(\mathrm{k}^{\prime}\right)$ for uranium was 0.2 . Hence, sepa- 


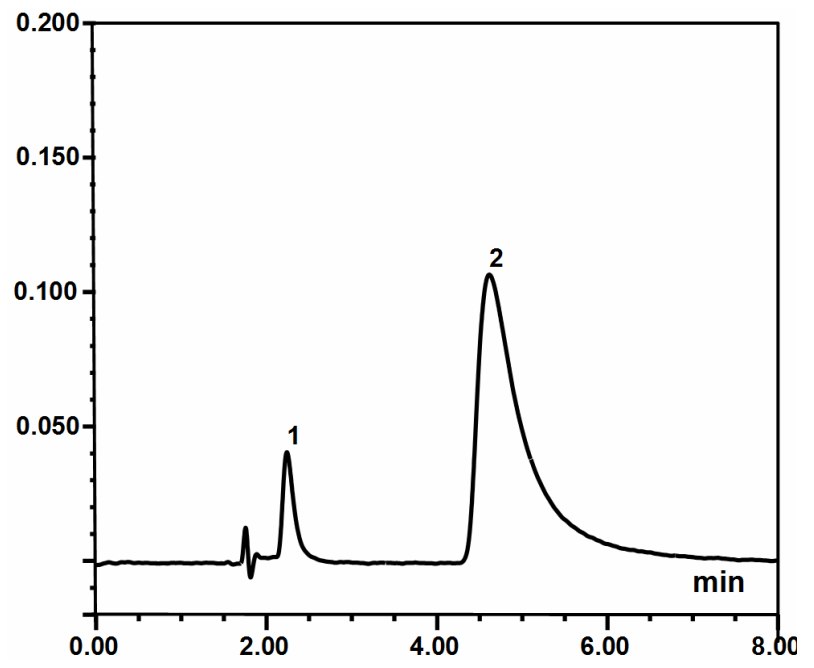

Figure 5. Chromatogram obtained for a standard mixture solution containing $U$ and Th. Peaks (1) U(VI) 1 ppm and (2) Th(IV) 2.5 ppm. Column: IonPac CS5A (4 $250 \mathrm{~mm})$. Elu-

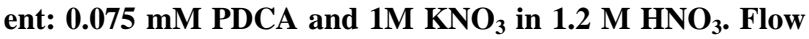
rate: $1 \mathrm{~mL} / \mathrm{min}$. Detection: Post column addition with $4.5 \times$ $10^{-5} \mathrm{M}$ Arsenazo-III in $0.1 \mathrm{~N} \mathrm{HNO}_{3}$ at $656 \mathrm{~nm}$; flow rate: 0.8 $\mathrm{mL} / \mathrm{min}$.

ration of trace Th from bulk uranium may be feasible because most of the uranium may get excluded along with solvent front, which can reduce the possibility of column swamping. Several synthetic samples in duplicates having U/Th ratios $1,2,20,200,400$ and $1.8 \times 10^{4}$ were prepared and injected for Th separation. The observed recoveries for $\mathrm{Th}$ in each case have been listed in Table 1 and the recoveries of Th were found to be more than $90 \%$, which showed that the method has high tolerance for uranium and hence, the direct separation of Th from the dissolved uranium samples is feasible.

\subsection{Calibration and Method Validation}

Since the success of an analytical method is critically dependent upon how accurately the concentrations of the analytes are known and how closely the matrix of the standards match with that of the samples to be analyzed, construction of a calibration plot in presence of matrix is desirable as the instrumental response is read in an almost identical chemical environment for both samples and calibration standards. This will compensate the matrix effect on the measurements. Therefore, high purity $\mathrm{UO}_{2}$ was dissolved in nitric acid and the solution was made up to a known volume. Several aliquots were prepared and varying volumes of a standard Th solution were spiked except for one aliquot. The spiked aliquots were made up to a known volume keeping a final concentration of $U$ in all aliquots at $87 \mathrm{mg} / \mathrm{mL}$. A calibration plot was constructed between the peak areas and their respective $\mathrm{Th}$ concentrations in the presence of matrix uranium ( $87 \mathrm{mg}$ of $\mathrm{U} / \mathrm{mL}$ of the standard solution), which showed a linear relation with a regression coefficient of 0.9975 and the plot obtained is shown in Figure 6.

The Th content of the uranium blank solution was calculated from the intercept of the plot. The limit of detection (LOD) was calculated as $0.1 \mathrm{ppm}$ of Th using $\mathrm{S} / \mathrm{N}=3$ formula. The method was validated by analyzing a $\mathrm{U}_{3} \mathrm{O}_{8}$ reference material (ILCE-IV) employing both the present method and ICP-MS (a well established procedure $[9,39]$ for the separation of trace Th from the uranium matrix prior to the ICP-MS analysis was followed). Accurately weighed quantities $(\sim 0.4 \mathrm{~g})$ of this $\mathrm{U}_{3} \mathrm{O}_{8}$ reference material were dissolved in $\mathrm{Conc} . \mathrm{HNO}_{3}$ and heated to dryness. Further they were re-dissolved in $5 \mathrm{~mL}$ of 0.5 $\mathrm{M} \mathrm{HNO}_{3}$ and injected into the IC for separation. Another set of dissolved samples were subjected to solvent extraction for the removal of matrix $U$ using aliquat-336 [40] and the final separated fractions were taken in $0.5 \mathrm{M}$ $\mathrm{HNO}_{3}$. The values obtained are listed in Table 2 and they are in good agreement with the mean value reported by the ICP-MS method. The chromatograms obtained for a direct injection is shown Figure 7.

\subsection{Procedure and Sample Analysis}

A sample size of $0.4-0.5 \mathrm{~g}$ was dissolved in Conc. $\mathrm{HNO}_{3}$

Table 1. Effect of concentration of $U$ (matrix) on the separation of $\mathrm{Th}$.

\begin{tabular}{cccccc}
\hline $\begin{array}{c}\text { Sample } \\
\text { Code }\end{array}$ & $\begin{array}{c}{\left[\mathrm{UO}_{2}^{2+}\right]} \\
\mu \mathrm{g} / \mathrm{mL}\end{array}$ & $\begin{array}{c}{\left[\mathrm{Th}^{4+}\right]} \\
\mu \mathrm{g} / \mathrm{mL}\end{array}$ & $\begin{array}{c}\mathrm{U} / \mathrm{Th} \\
\text { ratio }\end{array}$ & $\begin{array}{c}\text { Observed } \\
{[\mathrm{Th}] \mu \mathrm{g} / \mathrm{mL}}\end{array}$ & $\begin{array}{c}\text { Recovery } \\
\mathrm{Th} \%\end{array}$ \\
\hline $\mathrm{S}-1$ & 5 & 5 & 1 & 4.9 & 98.0 \\
$\mathrm{~S}-2$ & 10 & 5 & 2 & 4.78 & 95.6 \\
$\mathrm{~S}-3$ & 100 & 5 & 20 & 4.81 & 96.2 \\
S-4 & 1000 & 5 & 200 & 4.85 & 97.0 \\
S-5 & 2000 & 5 & 400 & 4.65 & 93.0 \\
S-6 & 88,000 & 5 & $1.8 \mathrm{E}^{4}$ & 4.73 & 94.6 \\
\hline
\end{tabular}

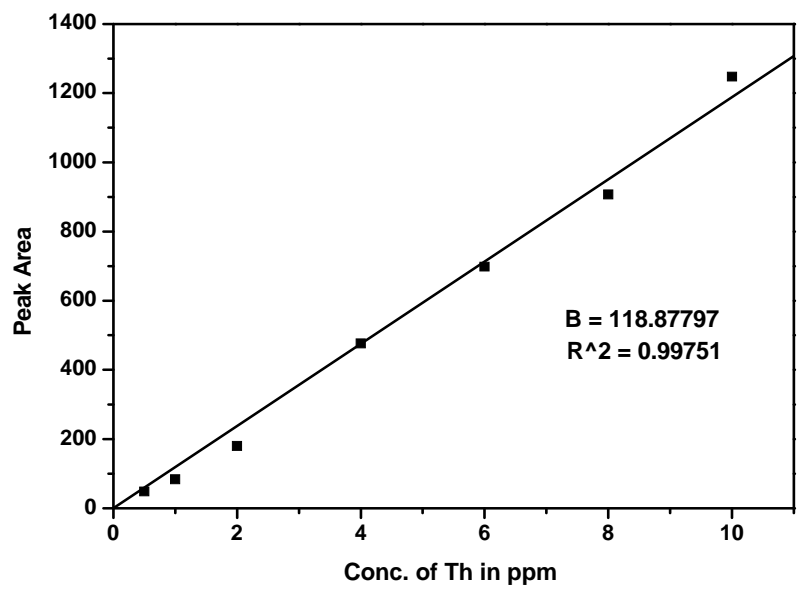

Figure 6. Calibration plot obtained for Th over a concentration range of $0.25-10 \mathrm{ppm}$ in the presence of $87 \mathrm{mg}$ of $\mathrm{U} /$ $\mathrm{mL}$ of the standard solutions. 
Table 2. Results obtained for a $\mathrm{U}_{3} \mathrm{O}_{8}$-reference material.

\begin{tabular}{|c|c|c|c|c|}
\hline $\begin{array}{c}\text { Sample } \\
\text { Analysis }\end{array}$ & $\begin{array}{l}\text { Sample } \\
\text { Code }\end{array}$ & $\begin{array}{c}{\left[\mathrm{Th}^{4+}\right] \text { by IC }} \\
\left(\mathrm{ppm}_{\mathrm{w}}\right)^{\mathrm{b}}\end{array}$ & Mean & $\begin{array}{c}\text { Mean reported } \\
\text { by ICP-MS }\end{array}$ \\
\hline \multirow{5}{*}{$\begin{array}{c}\text { Direct } \\
\text { Analysis }^{\mathrm{a}}\end{array}$} & D-1 & 75.5 & \multirow{5}{*}{$74.0 \pm 1.6$} & \\
\hline & D-2 & 72.7 & & \\
\hline & D-3 & 74.6 & & \\
\hline & D-4 & 71.8 & & \\
\hline & D-5 & 75.2 & & \\
\hline \multirow{5}{*}{$\begin{array}{c}\text { After } \\
\text { Solvent } \\
\text { Extraction }^{\mathrm{c}}\end{array}$} & & & \multirow{5}{*}{$71.4 \pm 1.3$} & $72.5 \pm 2.2$ \\
\hline & S-1 & 72.3 & & \\
\hline & S-2 & 69.8 & & \\
\hline & S-3 & 72.7 & & \\
\hline & S-4 & 70.9 & & \\
\hline
\end{tabular}

${ }^{\mathrm{a}} 0.5 \mathrm{~g}$ of sample dissolved and made up to $\sim 20 \mathrm{~g}$ by $0.1 \mathrm{~N} \mathrm{HNO}_{3}$ and $50 \mu \mathrm{L}$ of this solution was injected into IC. beach value quoted is a mean obtained from three replicate injections. ${ }^{\mathrm{c}} 0.5 \mathrm{~g}$ of sample was dissolved in $\mathrm{HCl}$ and $\mathrm{U}$ was separated by aliquat-336 [40]in $6 \mathrm{M} \mathrm{HCl}$.

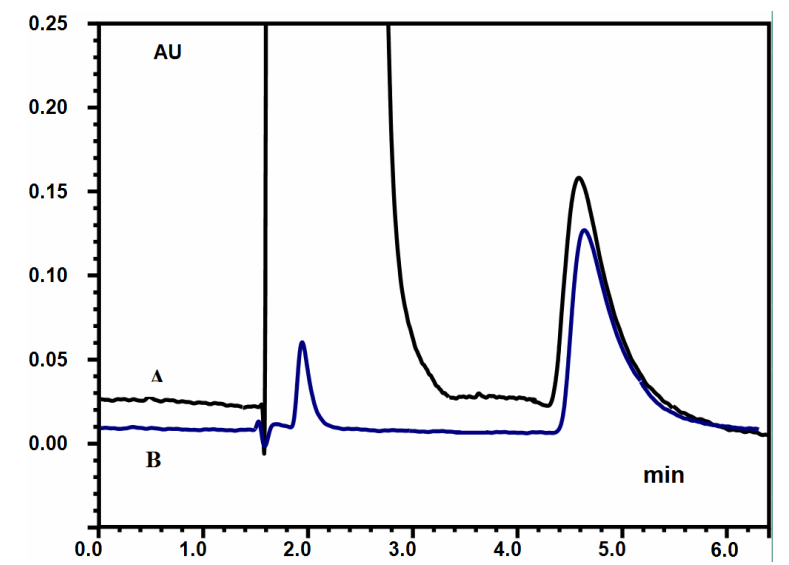

Figure 7. Typical chromatograms obtained for a $U_{3} O_{8}-\mathrm{Re}-$ ference material sample (A) direct injection of dissolved uranium solution (B) sample injected after removal of uranium (matrix) by solvent extraction.

and evaporated to dryness. Further, it was re-dissolved in $0.5 \mathrm{M} \mathrm{HNO}_{3}$ to have a final volume of $5 \mathrm{~mL}$ and $50 \mu \mathrm{L}$ of this solution was injected into IC for separation. A mobile phase of $0.075 \mathrm{mM}$ PDCA and $1 \mathrm{M} \mathrm{KNO}_{3}$ in $1.2 \mathrm{M} \mathrm{HNO}_{3}$ was used at a flow rate of $1 \mathrm{~mL} / \mathrm{min}$ forseparation. The separated fraction of metals are detected and measured by post column addition of $4.5 \times$ $10^{-4} \mathrm{M}$ arsenazo-III at a flow rate of $0.8 \mathrm{~mL} / \mathrm{min}$. The results obtained for typical samples are listed in Table 3.

\section{Conclusion}

The proposed method was successfully used for the determination of trace levels of Th in uranium matrix without employing prior separation of matrix. The method is simple, rapid, accurate and promising for its adaptation in the routine quality control analysis of uranium based
Table 3. Results obtained for uranium samples.

\begin{tabular}{cc}
\hline Sample & Conc. of Th $\left(\mathrm{ppm}_{\mathrm{w}}\right)^{\mathrm{a}}$ \\
\hline $\mathrm{UO}_{2}-\mathrm{SG}$ & $18.3 \pm 1.3$ \\
$\mathrm{U}_{3} \mathrm{O}_{8}-\mathrm{NFC}-1$ & $15.7 \pm 1.4$ \\
$\mathrm{U}_{3} \mathrm{O}_{8}-\mathrm{NFC}-2$ & $23.6 \pm 1.7$ \\
\hline
\end{tabular}

${ }^{a}$ mean of three analyses.

fuels.

\section{Acknowledgements}

The authors thank Dr. B. S. Tomar, Head, Radioanalytical Chemistry Division, BARC for his support. They also thank Mr. V. G. Mishra, RACD for his help.

\section{REFERENCES}

[1] H. J. Bhabha and N. B. Prasad, "A Study of the Contribution of Atomic Energy to a Power Programme in India," Proceedings of the Second United Nations International Conference on the Peaceful Uses of Atomic Energy, Geneva, Vol. 1, September 1958, pp. 89-101.

[2] M. Dayal, S. R. Paranjape, B. Singh and N. B. Prasad, "Study of Fuel Cycles with Reference to a Power Programme," Proceedings of the Second United Nations International Conference on the Peaceful Uses of Atomic Energy, Geneva, Vol. 13, September 1958, pp. 184-194.

[3] T. K. Mukherjee, "Characterization and Quality Control of Nuclear Fuels (CQCNF-2002)," Allied Publishers, New Delhi, 2003.

[4] IAEA-TECDOC-1450, "Thorium Fuel Cycle-Potential Benefits and Challenges", IAEA, Austria, 2005, pp. 6869.

[5] V. Venugopal, "Chemical Quality Control of Nuclear Materials," Indian Association for Nuclear Scientists and Allied Chemists (IANCAS) Bulletin, Vol. 4, Mumbai, 2005.

[6] S. Joannon, P. Telouk, C. Pin, "Determination of U and Th at Ultra-Trace Levels by Isotope Dilution Inductively Coupled Plasma Mass Spectrometry Using a GeyserType Ultrasonic Nebulizer: Application to Geological Samples," Spectrochimica Acta B, Vol. 52, No. 12, 1997. pp. 1783-1789.

http://dx.doi.org/10.1016/S0584-8547(97)00072-4

[7] A. G. Adriaens, J. D. Fassett, W. R. Kelly, D. S. Simons and F. C. Adams, "Determination of Uranium and Thorium Concentrations in Soils: Comparison of Isotope Dilution-Secondary Ion Mass Spectrometry and Isotope Dilution-Thermal Ionization Mass Spectrometry," Analytical Chemistry, Vol. 64, No. 23, 1992, pp. 2945-2950. http://dx.doi.org/10.1021/ac00047a012

[8] E. H. Borai and A. S. Mady, "Separation and Quantification of ${ }^{238} \mathrm{U},{ }^{232} \mathrm{Th}$ and Rare Earths in Monazite Samples by Ion Chromatography Coupled with On-Line Flow Scintillation Detector," Applied Radiation and Isotopes, Vol. 57, No. 4, 2002. pp. 463-469. http://dx.doi.org/10.1016/S0969-8043(02)00089-1

[9] S. B. Deb, M. K. Saxena, B. K. Nagar and K. L. Rama- 
kumar, "Determination of Trace Amounts of Thorium in a Uranium Matrix by Inductively Coupled Plasma Mass Spectrometry and Validation of the Separation Procedure by Standard Addition and Tracer Techniques," Atomic Spectroscopy, Vol. 29, No. 2, 2008, pp. 39-44.

[10] F. Hao, B. Paull and P. R. Haddad, "Determination of Thorium and Uranyl in Nitrophosphate Solution by OnLine Matrix-Elimination Reversed-Phase Chromatography," Chromatographia, Vol. 42, No. 11-12, 1996, pp. 690-696. http://dx.doi.org/10.1007/BF02267703

[11] F. Hao, B. Paull and P. R. Haddad, "Determination of Trace Levels of Thorium(IV) and Uranyl by ReversedPhase Chromatography with On-Line Preconcentration and Ligand Exchange," Journal of Chromatography A, Vol. 749, No. 1-2,1996, pp. 103-113. http://dx.doi.org/10.1016/0021-9673(96)00450-5

[12] R. M. Cassidy, "Determination of Rare-Earth Elements in Rocks by Liquid Chromatography," Chemical Geology, Vol. 67, No. 3-4, 1998. pp. 185-195. http://dx.doi.org/10.1016/0009-2541(88)90127-1

[13] P. E. Jackson, J. Carnevale, H. Fuping and P. R. Haddad, "Determination of Thorium and Uranium in Mineral Sands by Ion Chromatography," Journal of Chromatography A, Vol. 671, No. 1-2, 1996, pp. 181-191. http://dx.doi.org/10.1016/0021-9673(94)80237-8

[14] R. M. C Sutton, S. J. Hill, P. Jones, A. Sanz-Medel and J. I. Garcia-Alonso, "Comparison of the Retention Behaviour of Uranium and Thorium on High-Efficiency Resin Substrates Impregnated or Dynamically Coated with Metal Chelating Compounds," Journal of Chromatography A, Vol. 816, No. 2, 1998, pp. 286-291. http://dx.doi.org/10.1016/S0021-9673(98)00496-8

[15] R. M. Cassidy and M. Fraser, "Equilibria Effects in the Dynamic Ion-Exchange Separation of Metal Ions," Chromatographia, Vol. 18, No. 7, 1984, pp. 369-373. http://dx.doi.org/10.1007/BF02262483

[16] P. Jones and P. N. Nesterenko, "High-Performance Chelation Ion Chromatography a New Dimension in the Separation and Determination of Trace Metals," Journal of Chromatography A, Vol. 789, No. 1-2, 1997, pp. 413-435. http://dx.doi.org/10.1016/S0021-9673(97)00824-8

[17] Ch. S. K. Raju, M. S. Subramanian, N. Sivaraman, T. G. Srinivasan and P. R. Vasudeva Rao, "Retention Studies on Uranium, Thorium and Lanthanides with Amide Modified Reverse Phase Support and Its Applications," Journal of Chromatography A, Vol. 1156, No. 1-2, 2007, pp. 340-347. http://dx.doi.org/10.1016/j.chroma.2007.01.010

[18] M. Akhila Maheswari, D. Prabhakaran, M. S. Subramanian, N. Sivaraman, T. G. Srinivasan and P. R. Vasudeva Rao, "High Performance Liquid Chromatographic Studies on Lanthanides, Uranium and Thorium on Amide Modified Reversed Phase Supports," Talanta, Vol. 72, No. 2, 2007, pp. 730-740. http://dx.doi.org/10.1016/j.talanta.2006.12.003

[19] F. Hao, B. Paull and P. R. Haddad, "Retention Behaviour of Thorium(IV) and Uranyl on a Reversed-Phase Column with Glycolate and Mandelate as Eluents," Journal of Chromatography A, Vol. 739, No. 1-2, 1996, pp. 151-161. http://dx.doi.org/10.1016/0021-9673(96)81462-2
[20] M. J. Shaw, S. J. Hill and P. Jones, "Chelation Ion Chromatography of Metal Ions Using High Performance Substrates Dynamically Modified with Heterocyclic Carboxylic Acids," Analytica Chimica Acta, Vol. 401, No. 1-2, 1999, pp. 65-71.

http://dx.doi.org/10.1016/S0003-2670(99)00495-X

[21] P. Jones, "Major Sensitivity Improvements in Ion Chromatography Determinations Involving Post-Column Spectrophotometric Reaction Detectors through Elimination of Pump Noise Using a Dual Wavelength Monitoring Procedure," Analyst, Vol. 125, No. 5, 2000, pp. 803-806. http://dx.doi.org/10.1039/b001826k

[22] M. J. Shaw, S. J. Hill, P. Jones and P. N. Nesterenko, "Determination of Uranium in Environmental Matrices by Chelation Ion Chromatography Using a High Performance Substrate Dynamically Modified with 2,6-Pyridinedicarboxylic Acid," Chromatographia, Vol. 51, No. 11-12, 2000, pp. 695-700. http://dx.doi.org/10.1007/BF02505407

[23] S. Jeyakumar, V. G. Mishra, M. K. Das, V. V. Raut, R. M. Sawant and K. L. Ramakumar, "Separation Behavior of $\mathrm{U}(\mathrm{VI})$ and $\mathrm{Th}(\mathrm{IV})$ on a Cation Exchange Column Using 2,6-Pyridine Dicarboxylic Acid as a Complexing Agent and Its Application for the Rapid Separation and Determination of U and Th by Ion Chromatography," Journal of Separation Science, Vol. 34, No. 6, 2011, pp. 609-616. http://dx.doi.org/10.1002/jssc.201000907

[24] J. Cowan, M. J. Shaw, E. P. Achterberg, P. Jones and P. N. Nesterenko, "The Ion Chromatographic Separation of High Valence Metal Cations Using a Neutral Polystyrene Resin Dynamically Modified with Dipicolinic Acid," Analyst, Vol.125, No. 12, 2000, pp. 2157-2159. http://dx.doi.org/10.1039/b008235j

[25] "Determiantion of Uranium and Thorium in Complex Matrices Using Chelation Ion Chromatography," Dionex Application Note, No. 79, 1998, LPN 034670-01.

[26] A. W. Al-Shawi and R. Dahl, "Determination of Thorium and Uranium in Nitrophosphate Fertilizer Solution by Ion Chromatography," Journal of Chromatography A, Vol. 706, No. 1-2, 1995. pp. 175-181. http://dx.doi.org/10.1016/0021-9673(95)00006-9

[27] M. P. Harrold, A. Siriraks and J. Riviello, "High-Performance Ion Chromatographic Separation of Uranium and Thorium in Natural Waters and Geological Materials," Journal of Chromatography A, Vol. 602, No. 1-2, 1992, pp. 119-125. http://dx.doi.org/10.1016/0021-9673(92)80071-2

[28] F. Nelson, T. Murase and K. A. Kraus, "Ion Exchange Procedures. I. Cation Exchange in Concentration $\mathrm{HCl}$ and $\mathrm{HClO}_{4}$ Solutions," Journal of Chromatography A, Vol. 13, 1964, pp. 503-535.

http://dx.doi.org/10.1016/S0021-9673(01)95146-5

[29] H. Hojabri, A. G. Lavin, G. G. Wallace and J. M. Riviello, "Determination of Metal Ions Using Ion Chromatography and Indirect Amperometric Detection," Analytical Chemistry, Vol. 59, No. 1, 1987, pp. 54-57. http://dx.doi.org/10.1021/ac00128a011

[30] Y. S. Park, S. H. Han, K. S. Joe, T. Y. Eom and G. Lee, "Retention Behaviour of Transition Metal Ions with Some 
Complexing Agents on Cation Exchanger," Bulletin of the Korean Chemical Society, Vol. 14, No. 6, 1993. pp. 692-696.

[31] N. Cardellicchio, P. Ragone, S. Cavalli and J. Riviello, "Use of Ion Chromatography for the Determination of Transition Metals in the Control of Sewage-TreatmentPlant and Related Waters," Journal of Chromatography A, Vol. 770, No. 1-2, 1997, pp. 185-193. http://dx.doi.org/10.1016/S0021-9673(97)00086-1

[32] E. H. Borai, M. A. Eid and H. F. Aly, "Determination of REEs Distribution in Monazite and Xenotime Minerals by Ion Chromatography and ICP-AES," Analytical and Bioanalytical Chemistry, Vol. 372, No. 4, 2002, pp. 537541. http://dx.doi.org/10.1007/s00216-001-1204-8

[33] L. Perna, F. Bocci, L. Aldave de las Heras, J. De Pablob and M. Betti, "Studies on Simultaneous Separation and Determination of Lanthanides and Actinides by Ion Chromatography Inductively Coupled Plasma Mass Spectrometry Combined with Isotope Dilution Mass Spectrometry," Journal of Analytical Atomic Spectrometry, Vol. 17, 9, 2002, pp. 1166-1171. http://dx.doi.org/10.1039/b202451a

[34] P. Janvion, S. Motellier and H. Pitsch, "Ion-Exchange Mechanisms of Some Transition Metals on A Mixed-Bed Resin with a Complexing Eluent," Journal of Chromatography A, Vol. 715, No. 1, 1995, pp. 105-115. http://dx.doi.org/10.1016/0021-9673(95)00576-9
[35] M. Xavier, P. R. Nair, K. V. Lohithakshan, S. G. Marathe and H. C. Jain, "Determination of Uranium in the Presence of Iron and Plutonium by Ti(III) Reduction and Biamperometric Titration," Journal of Radioanalytical and Nuclear Chemistry, Vol. 148, No. 2, 1991, pp. 251256. http://dx.doi.org/10.1007/BF02060358

[36] L. G. Sillen and A. E. Martell, "Stability Constants of Metal Ion Complexes, spl," Chemical Society, London, 1964, p. 545.

[37] P. R. Haddad and R. C. Foley, "Modelling of Cation Retention in Ion Chromatography Using Fixed-Site and Dynamically Coated Ion-Exchange Columns," Journal of Chromatography A, Vol. 500, 1990, pp. 301-312. http://dx.doi.org/10.1016/S0021-9673(00)96073-4

[38] A. E. Martell and R. M. Smith "Critical Stability Constants," Vol. I, Amino Acids, Plenum, New York, 1974, p. 377.

[39] "DAE-Interlaboratory Comparison Experiment (ILCE) for Trace Metal Assay of Uranium," Phase 2, Document, BARC, India, 2002.

[40] V. R. Bhandiwad, R. Swarup and S. K. Patil, "Extraction of Actinides by Quaternary Amines from Hydrochloric Acid Medium," Journal of Radioanalytical Chemistry, Vol. 52, No. 1, 1979, pp. 5-14. http://dx.doi.org/10.1007/BF02517694 